\title{
Co-evolution of "race-to-fish" dynamics and declining size structures in an expanding commercial coral-reef fishery
}

\author{
Javier Cuetos-Bueno $•$ Dalia Hernandez-Ortiz $・$ Peter Houk
}

Received: 15 April 2018/Accepted: 19 October 2018/Published online: 7 November 2018

(C) The Author(s) 2018

\begin{abstract}
Spatial expansions can provide a false sense of sustainability to fish markets and their consumers who perceive stable landings through time despite localized depletions. This study examined attributes of monthly landings and changes in size structures within a commercial coral-reef fishery that had stable landings for 11 years. Regression models revealed a significant rise in the ratio of landings between calm and windy months, depicting that stable landings were driven by increased fishing effort or success during the calmer months when less exploited reefs became accessible. Within the calmer months, "race-to-fish" dynamics also evolved for some target species, such as parrotfishes, whose landings became increasingly concentrated towards the onset of calm favorable conditions. During this same time, the size structure for 15 out of 19 target species that comprised $60 \%$ of annual landings decreased. The cumulative results suggested that (1) spatial management units can be improved by taking
\end{abstract}

Electronic supplementary material The online version of this article (https://doi.org/10.1007/s11160-018-9542-1) contains supplementary material, which is available to authorized users.

J. Cuetos-Bueno $(\bowtie) \cdot$ D. Hernandez-Ortiz $\cdot$ P. Houk University of Guam Marine Laboratory, Mangilao, Guam e-mail: javiercuetos@gmail.com

J. Cuetos-Bueno

The Nature Conservancy Micronesia Program, Koror, Palau environmental gradients that define fishing access into consideration, and (2) thresholds for size-and-agebased policies should be established with respect to life-history parameters that maximize cohort production and protect against declining size structures. Both recommendations resonate with traditional forms of management across the Pacific that were based on reef tenure and knowledge of how species respond to fishing pressure.

Keywords Coral-reef fisheries · Fisheries expansions $\cdot$ Localized depletions $\cdot$ Race-to-fish dynamics $\cdot$ Size-structure management

\section{Introduction}

Subsistence coral-reef fisheries were historically managed through small-scale reef tenure systems that intertwined many principles of fisheries management into tradition and culture, generally providing for sustainable harvesting regimes (Johannes 1978; Mcclenachan and Kittinger 2013; Birkeland 2017). In contrast, the development of commercial coral-reef fisheries and fisheries technology over the second half of the twentieth century removed key links between management and society, often resulting in fisheries depletions (Cuetos-Bueno and Houk 2014; Pauly and Zeller 2014; Houk et al. 2018b; Rhodes et al. 2018). Capturing where coral-reef fisheries reside along this 
historical-to-modern exploitation gradient remains difficult because long-term datasets that can quantify harvesting patterns and potential depletions are rare (Claro et al. 2009; Pauly and Zeller 2014). More important to the present study, even less has been documented about the nature of spatial expansions in fisheries with growing exploitation, and how expansions might be quantified.

Localized fisheries depletions are followed by spatial expansions because infrastructure and equipment are committed to keep up with market demand (Birkeland 2004; Swartz et al. 2010; Cinner et al. 2016; Cuetos-Bueno and Houk 2017). For coral reefs, localized depletions are followed by expansions to less accessible (windward, further, and deeper) reefs that historically had less fishing pressure (Teh et al. 2007; Lindfield et al. 2015; Albert et al. 2015). While expansions may provide a consistent supply of fresh fish to demand-driven markets, they also mask localized depletions and increase catch variability (Crona et al. 2016). Variability increases because fisheries landings become more dependent upon pulsed environmental conditions that provide limited access to less-exploited resources (e.g., calm seasons, calm days, or reproductive events), while accessible reefs become depleted with persistent fishing pressure (Abesamis et al. 2014; Taylor et al. 2014a). This general hypothesis was furthered within the present study that focused on a commercial coral-reef fishery in Micronesia that was exposed to several decades of persistent fishing pressure.

Previous studies in Micronesia have reported increased variability in reef-fish landings in accordance with growing human populations (Houk et al. 2012). This trend was driven by catch success becoming increasingly dependent on opportunistic moon phases and weather conditions that provided better acccess to fisheries resources (i.e., calm periods with low winds and low lunar illumination). These findings were supported by a subsequent study on Guam, the urban center of Micronesia, where windward reefs were compared to seasonal no-take marine protected areas because trade winds limited access to the northern and eastern shorelines for part of the year (Taylor et al. 2014a). Elsewhere in Kosrae, Federated States of Micronesia, growing differences in fish populations between windward and leeward reefs were found across 30 years that were predicted by fishing access (McLean et al. 2016). Modern fishing pressure in Kosrae has now shifted to the windward reefs during the calm season (Houk et al. 2017). This redistribution of fishing effort to improve fishing success at wave-exposed fishing grounds was also observed in other Pacific locales (Hernandez-Ortiz et al. 2016). In sum, these studies revealed that both stock status and fishing success between more and less accessible reefs is expected to grow with fishing pressure (Abesamis et al. 2014; Taylor et al. 2014a; Fig. 1a).

Eventually, growing variability is expected to amplify seasonal peaks in landings, such as improved catches at the onset of calm months when many target species are most susceptible, or improved catches during spawning seasons (Claro et al. 2009; Hernandez-Ortiz et al. 2016; Houk et al. 2017). Within, we equate this to "race-to-fish" dynamics, as improved catch success and landings become concentrated at the start of a favorable timeframe or season, but rapidly decline to reference levels afterwards (Sys et al. 2017). Such "race-to-fish" dynamics have been identified in fisheries where access to less-exploited common-pool stocks is suddenly open (Huang et al. 2014; Birkenbach et al. 2017; Rosenberg 2017). Studies of "raceto-fish" dynamics on coral reefs have mainly examined periodic no-take marine protected areas that had high catch success and landings upon opening, but rapidly decreased after a few days to several months (McClanahan and Mangi 2000; Eggleston et al. 2003; Williams et al. 2006; Jupiter et al. 2012).

Eventually, changes in the composition and size structure of landings are also expected alongside fisheries expansions because habitat availability, technology, and cost ultimately limit access to new fishing grounds. Compensatory density dependence dictates that target species should shift in size structure with fishing pressure, as landings of large fish are increasingly being replaced by smaller and younger fish (Jennings et al. 1999; Shin et al. 2005). Species replacements can also occur as larger, slower-growing preferred target species become replaced by more resilient and less preferred counterparts that have stronger density dependence (Pauly et al. 1998; Kaunda-Arara et al. 2003; Houk et al. 2017). Both species replacement and size-structure changes have been suggested as useful indicators of changing stock status (Shin et al. 2005; Houk et al. 2017), and diminishing size-and-age structures form the basis for widely used fisheries management models that derive 

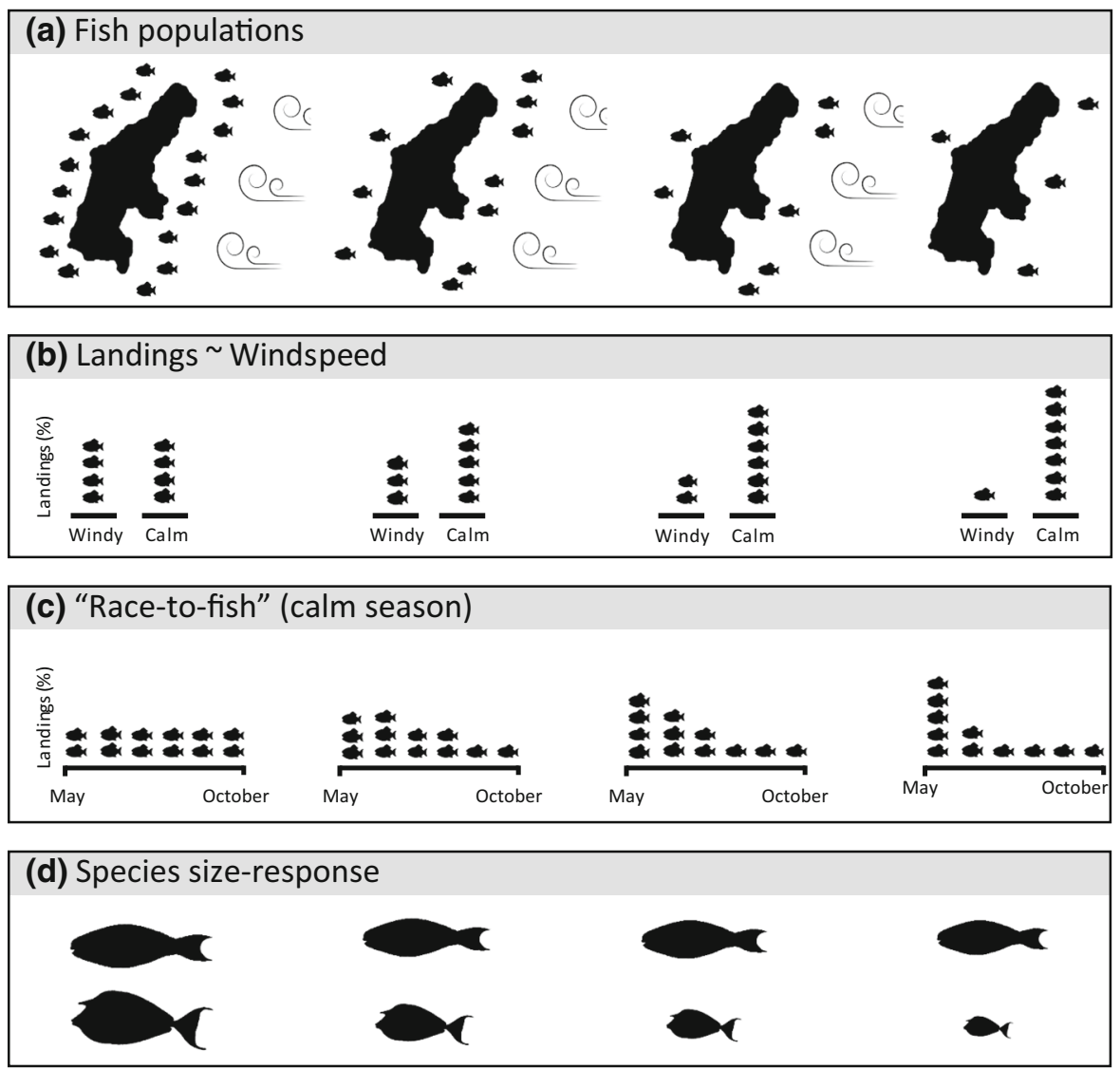

Fishing pressure/time

Fig. 1 Hypothesized responses to growing fishing pressure through time. Localized depletions are hypothesized to reduce fish stocks in the more accessible, leeward reefs through time (a) resulting in growing calm-versus-windy landings ratios (b). Within calm months, "race-to-fish" dynamics might evolve for

fishing-versus-natural mortality and spawning potential ratios (Nadon et al. 2015; Prince et al. 2015).

The present study first examined the evolution of catch variability and "race-to-fish" dynamics using unique governmental landings records across a 11-year period in a Micronesian coral-reef fishery exposed to high fishing pressure. Detailed records of monthly landings were used to assess changes in seasonal variability across the study period at different taxonomic levels. In addition, a limited set of species records from available datasets and published reports were used to examine changes in size structure across desirable target species once favorable conditions emerge (c). Alongside growing spatial gradients, fishing pressure is also expected to diminish size structures or result in the replacement of slower-growing species with faster-growing counterparts (d)

16 years. Together, the results help to reflect upon the current stock status and guide an improved management framework for coral-reef fisheries.

\section{Methods}

Study area

The Commonwealth of the Northern Mariana Islands (CNMI) is an archipelago in the Western Pacific Ocean spanning $700 \mathrm{~km}\left(14^{\circ}-20^{\circ} \mathrm{N}\right)$. The population 
of CNMI is distributed among three inhabited islands in the south of the archipelago (Saipan, Tinian, and Rota), containing $89 \%, 6 \%$, and $5 \%$ of the 53,883 inhabitants, respectively (U.S. Census Bureau 2014). Fishing plays a fundamental role in society, providing for food security, recreation, and income (Amesbury and Hunter-Anderson 2003; Van Beukering et al. 2006). Coral-reef fisheries in CNMI are dominated by night-time spearfishing (estimated $85 \%$ of overall landings in 2010), with less important contributions from bottom fishing and other fishing methods (Houk et al. 2012). Generalized declines in coastal fisheries have been hypothesized across recent decades alongside growing commercialization (Cuetos-Bueno and Houk 2014). Decadal fisheries declines were associated with expanding fisheries from historically-targeted shallow habitats inside the lagoons to further and deeper reefs across the archipelago (Smith 1947; Amesbury and Hunter-Anderson 2003; Houk et al. 2012; Cuetos-Bueno and Houk 2014; Smith and Marx 2016). The present study aimed to quantify the patterns and consequences of growing fishing variability using unique governmental records and data summarized from technical reports.

\section{Data sources}

All accessible datasets regarding CNMI's coral-reef fisheries were first identified, including (1) monthly landings gathered from the CNMI Nutrition Assistance Program (NAP; 2006-2016), (2) annual landings reported by the Western Pacific Fisheries Information Network (WPacFIN), and (3) published studies and technical reports describing species-based trends between 1993 and 2018 (Graham 1994a; Houk et al. 2012; Sundberg et al. 2015; Trianni et al. 2018). Species-based datasets collected by the CNMI Division of Fish and Wildlife (DFW) and others in collaboration with NOAA Pacific Islands Fisheries Science Center were not made available to the authors because datasets were classified as sensitive (Graham 1994a; Sundberg et al. 2015). A request to use only non-sensitive data was also declined. Therefore, size data from these reports were manually extracted from published histograms of a samll subset of target species. Each data source is further described below.

\section{Nutritional assistance program}

Currently, CNMI's Nutrition Assistance Program office collects mandatory monthly reports of purchases from all fish markets in Saipan (Cuetos-Bueno and Houk 2014). NAP reports describe purchases of fish at varying taxonomic levels, ranging from species level for some iconic fish (i.e., Naso unicornis), to generic groups (i.e., reef-fish). Data from January 2006 to December 2016 were manually entered into an electronic database. Data from main fish markets $(n=13)$ that contributed to at least $1 \%$ of overall landings were used for analyses. Data from 2015 were excluded due to severe impacts to fishing activities from Typhoon Soudelor that lasted several months (August 2015).

\section{WPacFIN dataset}

WPacFIN data included monthly purchase forms completed by the fish dealers that were classified at varying taxonomic resolution. While the survey form allows for classifying fishes at the family level, the majority of data were binned into an "assorted reeffish" category. Completed vendor forms were compiled by WPacFIN who expanded all landings by applying coverage factors to account for fish not captured by their monitoring program [estimated at 10\%; no further explanation provided, Lowe et al. 2016)]. Concerns regarding the reliability of these datasets have previously been reported due to methodological issues and inconsistent data collection efforts (Graham 1994b; Radtke and Davis 1995; CuetosBueno and Houk 2014). WPacFIN landings were extracted and compared with NAP data for the present study (https://www.pifsc.noaa.gov/wpacfin).

\section{Historical size-structure data}

CNMI DFW previously conducted a snapshot study of fisheries-dependent data from two Saipan-based commercial fishing operations in 1993 (Graham 1994a). Fishing operations were monitored weekly from February to October 1993, totaling 44 day-and-night spearfishing trips. Fish were identified to the species level and measured to the nearest $\mathrm{mm}$ fork length (FL). In total, 10,417 individual fish measurements were included in the report along with other catch attributes such as fishing location. Size-frequency data for 70 
species ( $\mathrm{N}=5205$ individuals $)$ from Saipan and Tinian islands were manually extracted from histograms contained in the report and digitized for comparisons.

Houk et al. (2012) collected daily fisheries-dependent data from four of the main Saipan fish markets from June to September 2009, and from December 2009 to January 2010. These data provided a snapshot of the two main fishing seasons and allowed for an annual extrapolation of landings. During daily visits, reef-fish $(\mathrm{n}=11,506)$ were measured to the nearest $\mathrm{cm}$ FL and identified. Landings were mainly derived from night freedive spearfishing, but illegal SCUBAassisted spearfishing was hypothesized to contribute to the landings based upon stronger similarities with Guam SCUBA landings compared to freedive landings. This hypothesis was further supported by anecdotal conversations with commercial fishers, despite the practice being illegal at the time of the research. Reported landings originated from fishing trips to the islands of Saipan, Tinian, and Rota, and included 102 different reef-fish species.

In 2010, the Pacific Islands Fisheries Science Center began a biosampling program that remains ongoing (Sundberg et al. 2015; Trianni et al. 2018). Market visits were conducted 3 days a week at main markets and opportunistically at other markets. Fish were measured to the nearest $\mathrm{mm}$ FL and identified to species level. Additional information was also recorded such as fishing effort and location. While these datasets were not available for the present study, summary tables and size-frequency histograms for six target species were extracted from a technical report (Sundberg et al. (2015), Lethrinus atkinsoni, Lethrinus obsoletus, Mulloidichthys flavolineatus, Naso unicornis, Parupeneus barberinus, and Siganus argenteus. Size frequency data included 45,912 fish measurements between December 2010 and December 2014.

\section{Environmental data}

Windspeed and precipitation data were collected for analyses of historical landings. Daily records were gathered from the weather station located at the Saipan International Airport (http://www7.ncdc.noaa.gov/ CDO). Mean monthly windspeeds and precipitations were estimated by averaging across days within each month. Long-term monthly means were also generated for the study period by averaging monthly means across years.

Data preparation and analysis

Total annual commercial landings from NAP records were extrapolated by increasing the reported landings from the main fish dealers by $10 \%$ to account for an estimated $90 \%$ coverage factor used in comparative studies (Lowe et al. 2016). We next examined NAP datasets to explore historical trends in landings with respect to windspeed, rainfall, and season. Windspeeds represent a significant environmental factor predicting fish landings in CNMI, and across Micronesia because high winds and wave limit fishing access (Houk et al. 2012, 2017; Taylor et al. 2014a; CuetosBueno et al. 2018). In contrast, previous studies have shown a weaker or non-significant contribution of rainfall which was also examined here. Beyond monthly estimates, we also examined seasons for some analyses using natural breaks in the wind and rain data to define seasons (Jenks and Coulson 1963). This process allowed us to contrast: (1) calm (May to October) versus windy (November to April), and (2) dry (November to July) versus wet (August to October). We were not able to examine the influence of moon phases because NAP data were aggregated by month.

Disturbances during the study period included Crown-of-thorns starfish outbreaks of varying magnitude in 1998 and again between 2003 and 2006 (Acanthaster planci, coral predator, Houk et al. 2014), a coral bleaching event in 2013 (Reynolds et al. 2014), and Typhoon Soudelor in 2015. Typhoon Soudelor caused direct impacts to commercial fishing activities that lasted several months so data from 2015 were excluded from further analyses. Ecological disturbances were not expected to influence target fishery species as they are known to have a greater effect upon coral-associated species such as damselfishes and small herbivores that are not sold commercially (Graham et al. 2007). No other economic or social factors existed to significantly alter the spatial distribution of fishing effort/location in a sequential and continuous manner across the study period. In addition, difference in size structure were examined alongside catch variability to provide a second metric of growing fishing pressure in our study region (see below). 
Due to varying taxonomic resolution within NAP datasets, historical trends for one species (N. unicor$n i s$ ), two functional groups (parrotfishes and rabbitfishes), and all reef-fish combined were examined. These accounted for $13.2 \%$ (N. unicornis), $39.6 \%$ (parrotfishes), and $4.5 \%$ (rabbitfishes) of estimated overall reef-fish landings in 2009 respectively (Houk et al. 2012). The premise for these analyses was that catch variability was expected to rise alongside growing fishing pressure through time (Anderson et al. 2008; Houk et al. 2012; Fig. 1a-c). We first examined whether landings became more dependent upon seasons using regression models describing how the ratio of landings between the calm:windy and dry:wet seasons shifted through time (Fig. 1b). Given a growing reliance upon the calm season through time, we also investigated "race-to-fish" dynamics by regressing monthly landings across the calm season for each year (Fig. 1c). In both instances, we compared the slope of annual regression models through time to test if annual relationship were changing. Linear and polynomial models were used to assess these trends, and the best fit was selected based upon $\mathrm{R}^{2}$ values, confidence intervals ( $P$ values), and complexity (AIC scores), while ensuring residuals were normally distributed.

Last, we examined size-frequency datasets for a subset of target species with sufficient data $(\mathrm{N}>50)$. The rational for exploring changes in size structure were: (1) fish were caught mainly during night spearfishing events with similar gears, hookah-assisted shallow water fishing (early 1990s), hypothesized mixture of freedive and illegal SCUBA (2009), and reported free diving (2010s), and (2) the use of different gears has been determined to have limited impact on species-specific sizes-at-capture if location is controlled for (Nadon et al. 2015). Further, differences in fishing methods would arguably lead to a conservative estimate of change through time because SCUBA-assisted spearfishing that occurred in the later timeframe is known to target larger individuals (Houk et al. 2018b). Shifts in size-structure were hypothesized alongside increasing variability and exploitation, but with differing intensities across species (Houk et al. 2017, 2018b). In total, these analyses assessed size-structure trends between 1993 and 2009 for 19 species that accounted for $60.7 \%$ and $60.5 \%$ of landings from Saipan and Tinian during both timeframes, respectively. Size-differences were also explored for four target species using 2010s data extracted from modern reports and studies. In addition to temporal trends in size structure, we examined spatial trends across the populated CNMI islands in 2009, representing a fishing-access gradient (Saipan, Tinian, and Rota). Spatial comparison were not possible for any other timeframes given data limitations. Kolmogorov-Smirnov (KS) tests were used to compare species size-structures across different timeframes and locations.

We last examined the results of species-specific size structure changes with respect to species vulnerability indices and optimal catch sizes (Beverton 1992; Cheung et al. 2005; Froese and Pauly 2016). The vulnerability index was derived from FishBase and is based upon life history and ecological traits known to concurrently contribute to species vulnerability (Froese and Pauly 2016). Optimal catch sizes were estimated using Hoenig (1983) and Beverton (1992) equations for species with published life-history data (Taylor et al. 2014c, 2016; Taylor and Cruz 2017).

\section{Results}

Data derived from CNMI NAP office monthly reports depicted that reef-fish landings were not significantly different between 2006 and 2016, with an estimated mean of $42.0 \mathrm{mt} \mathrm{year}^{-1}( \pm 1.2 \mathrm{SE})$, and a mean interannual variation of $12.3 \%( \pm 2.9)$, or $8.7 \%( \pm 2.1)$ when excluding 2015 when Typhoon Soudelor impacted fishing activities (Figure S1a-b). In contrast, estimates of annual reef-fish landings derived from WPacFIN vendor reports depicted lower mean annual landings (26.2 $\mathrm{mt}^{\text {year }}{ }^{-1} \pm 6.0$ ), higher inter-annual variation $(27.9 \% \pm 7.6$, or $31.1 \% \pm 7.8$ when excluding 2015), and a clear declining trend overtime that amounted to an $82 \%$ reduction between 2006 and $2015\left(P<0.001, \mathrm{R}^{2}=0.85\right.$, exponential decay, Figure S1a). Given previously reported methodological issues with WPacFIN datasets (see Methods), only NAP datasets were used for all remaining inter-annual trends described below.

NAP data revealed a significant increase in the ratio of annual landings between calm and windy seasons for both reef-fish $\left(P=0.049, \mathrm{R}^{2}=0.33\right.$; Fig. $2 \mathrm{a}$ and c) and parrotfish $\left(P=0.018, \mathrm{R}^{2}=0.46\right.$; Fig. $2 \mathrm{~b}$ and d), reflecting a growing dependence upon favorable calm seasons for maintaining stable annual landings 
(a)

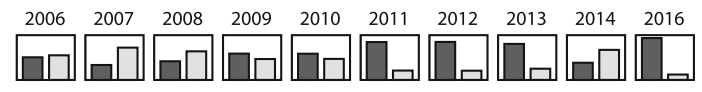

(c)

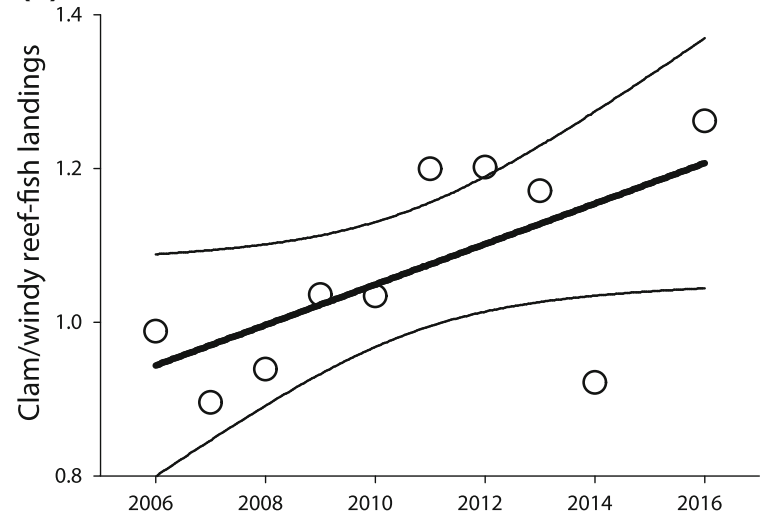

Fig. 2 Proportion of overall annual reef-fish (a) and parrotfish (b) landings caught during calm (dark gray bars) and winter (light gray bars) seasons. The annual differences between calm-

through time. Ratios of reef-fish and parrotfish landings between calm and windy season changed from $1: 1$ to $1.2: 1$ (or a $20 \%$ increase over 11 years), and from $0.7: 1$ to $1.7: 1$ (143\% increase), respectively. Similar trends were also found between monthly windspeeds and reef-fish landings within each year. Annual regression slopes between monthly windspeeds and reef-fish landings also revealed a growing dependency on calm months across the study period $\left(P=0.03, \mathrm{R}^{2}=0.41\right.$; Fig. 3a and $\left.\mathrm{c}\right)$. Interestingly, parrotfish landings didn't show a clear relationship with monthly mean windspeed, but instead had a strong and growing relationship with the start of the calm season, when wave-exposed reefs first become accessible to fishers. Regression slopes describing parrotfish landings across sequential calm season months became more negative across the study period, supporting the hypothesis of "race-to-fish" dynamics at the start of the calm season $\left(P \leq 0.001, \mathrm{R}^{2}=0.74\right.$; Fig. $3 b$ and $d)$. In contrast with total reef-fish and parrotfish landings, no clear patterns of increasing dependence upon favorable fishing conditions or "race-to-fish" dynamics were found for landings of rabbitfishes or N. unicornis. Additionally, no significant relationships were found between any landings and monthly rainfall, or between the rainy and dry season.

Comparisons of size-frequencies for target species across timeframes revealed that 15 out of the 19 fishes (b)

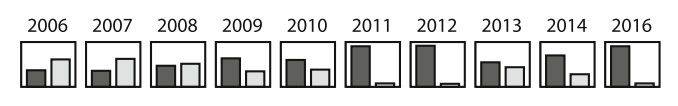

(d)

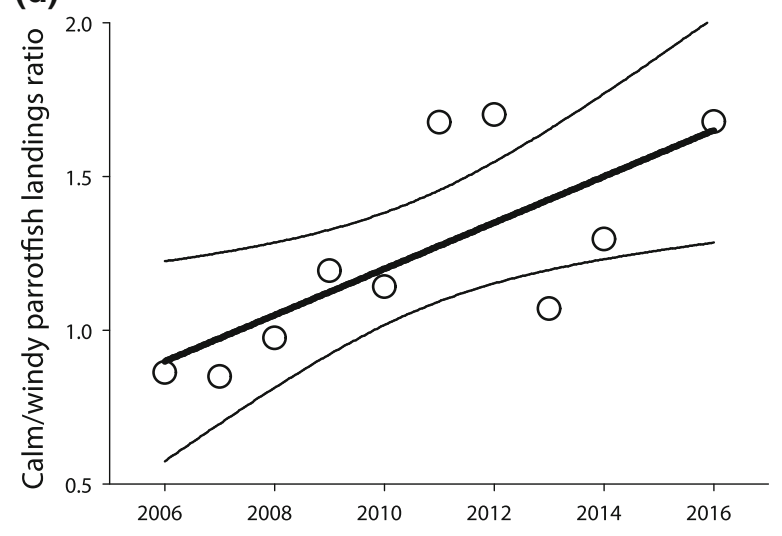

versus-windy landings were also examined across the study period for reef-fish (c) and parrotfish (d)

examined got smaller between 1993 and 2009, with stronger positive skews in their size frequency histograms (Fig. 4). In addition, three of the four species for which additional data were available in the 2010s showed further declines: $P$. barberinus, $N$. unicornis, and M. flavolineatus. However, a reverse trend was found for $S$. argenteus, which showed an increase in size between 2009 and 2010s. Significant declines in size structure ranged between $3.0 \%$ (or $8.3 \%$ in terms of biomass, Acanthurus lineatus) to $33.5 \%$ (or $71.4 \%$ in terms of biomass, Hipposcarus longiceps). Further, several species with recently published life history parameters showed an increase in the proportion of landings being captured below estimates of optimal capture sizes $\left(\mathrm{L}_{\text {opt }}\right)$ between 1993 and 2009 (H. longiceps, from 70 to $92 \%$, respectively; S. argenteus, from 49 to $90 \%$; and N. unicornis, from 90 to $95 \%$ ). The one species that showed a significant increase in size structure between 1993 and 2009 was the small-bodied soldierfish Myripristis berndti (4.0\% increase in size, or $11.2 \%$ in terms of biomass), while three other small-bodied species showed no significant changes (Heteropriacanthus cruentatus, Acanthurus olivaceus, and Scarus psittacus). We synthesized that the magnitudes of species-based declines in size structure between 1993 and 2009 were predicted by their vulnerability to fishing indices for most species $\left(P=0.101, \mathrm{R}^{2}=0.15\right.$; Fig. 5$)$. Yet, two species $(S$. argenteus, and $H$. longiceps) didn't appear to follow 
(a)

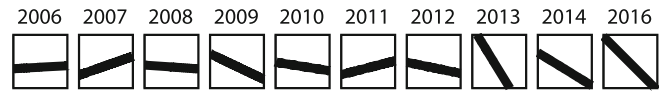

(c)

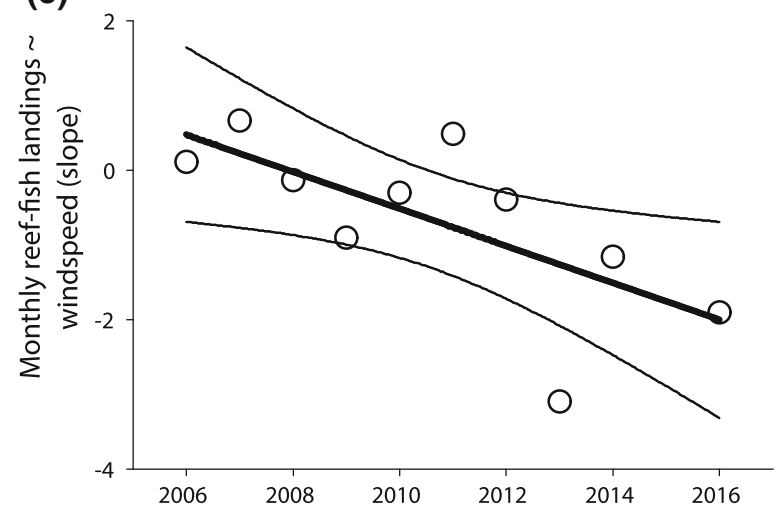

Fig. 3 Annual relationship between proportional monthly contribution to overall seasonal (calm) reef-fish landings and mean monthly windspeed (a), and between proportional contribution to overall seasonal parrotfish landings and months

this trend, as observed size declines were much larger than predicted by the overall relationship. When excluding these two species, the observed size changes were well predicted by the vulnerability to fishing index $\left(P=0.002, \mathrm{R}^{2}=0.47\right)$, essentially describing that fish with greater $\mathrm{L}_{\max }$ were most susceptible.

Last, geographical comparisons between the three populated islands in the CNMI using only the 2009 data portrayed the general trend of decreasing size structures with growing human presence and fishing access. Saipan, the island with the largest human population, consistently had smaller sizes for 6 out of 8 species analyzed compared to elsewhere (Figure S2). Largest differences existed for three target largebodied species (N. unicornis, Chlorurus microrhinos, and Scarus rubroviolaceus), as their mean sizes were $21.7 \%, 17.2 \%$ and $16.0 \%$ smaller in Saipan as compared to the remote and less-populated island of Rota respectively (or $50.8 \%, 44.0 \%$, and $43.1 \%$ in terms of biomass). Alternatively, two species (Kyphosus cinerascens and Mulloidichthys flavolineatus) were found to have significantly larger sizes in Saipan (13.8\% and $5.4 \%$ respectively) than elsewhere. (b)

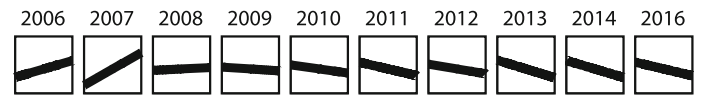

(d)

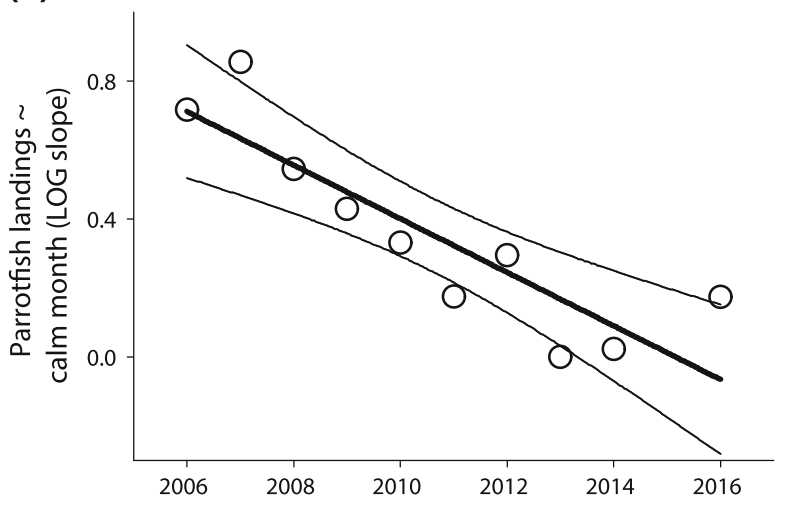

away from start of clam season (b). The growing significant of these annual relationships were examined across the study period for reef-fish (c) and parrotfish (d). Data points represent annual regression slopes

\section{Discussion}

The supply of fish to CNMI's commercial markets remained stable between 2006 and 2016. Yet, the present study revealed how stable landings were made possible due to a growing reliance on pulsed catch success during the calmer spring and summer months. Within the calm months, a "race-to-fish" dynamic further evolved for landings of some target species. Parrotfish landings were particularly sensitive to the onset of the calm season as calm-versus-windy landings ratios more than doubled over the study period, and landings also became concentrated towards the start of the calm season in May and June. These findings resonated with localized depletions of parrotfishes previously reported in the mid-1990s for the more accessible, leeward coast of the inhabited CNMI islands (Graham 1994a; Duenas \& Associates I 1997; Trianni 1998), and more recent reports in the 2010s (Houk et al. 2012, 2014). The present results also resonated with increased CPUEs during calm months between 2011 and 2014 (Trianni et al. 2018). Elsewhere on Guam, large parrotfish life histories were well predicted by fishing access and greater biomass and landings of large parrotfish were recorded on the windward eastern coast (Taylor et al. 2014a; Taylor and Cruz 2017; Houk et al. 2018b). In sum, the results suggested that stable commercial landings 
Fig. 4 Comparison of size frequencies for target species that comprised $60 \%$ of commercial landings across three different time periods (1993 light gray, 2009 gray, and 2010-2014 dark gray, $*$ indicates significance between all lines on the plot, $P<0.05$, Kolmogorov-Smirnov tests). These species all had sample sizes $\geq 50$ at each timeframe
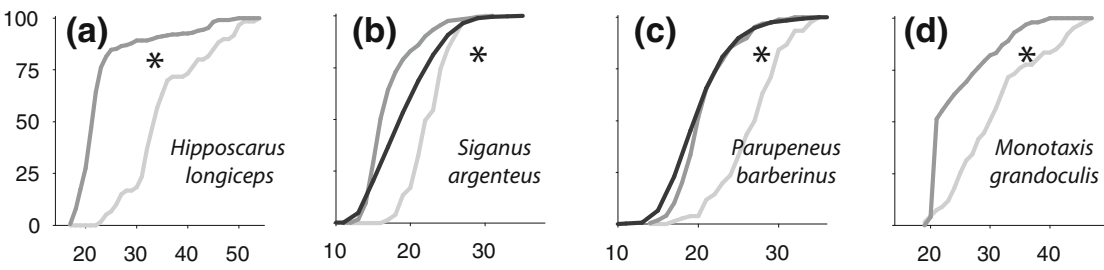

$2030 \quad 40$
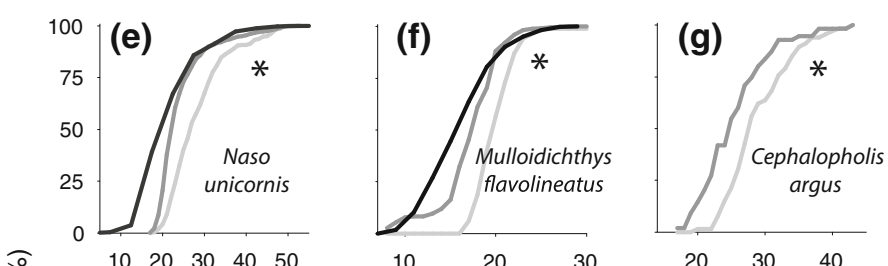

(h)
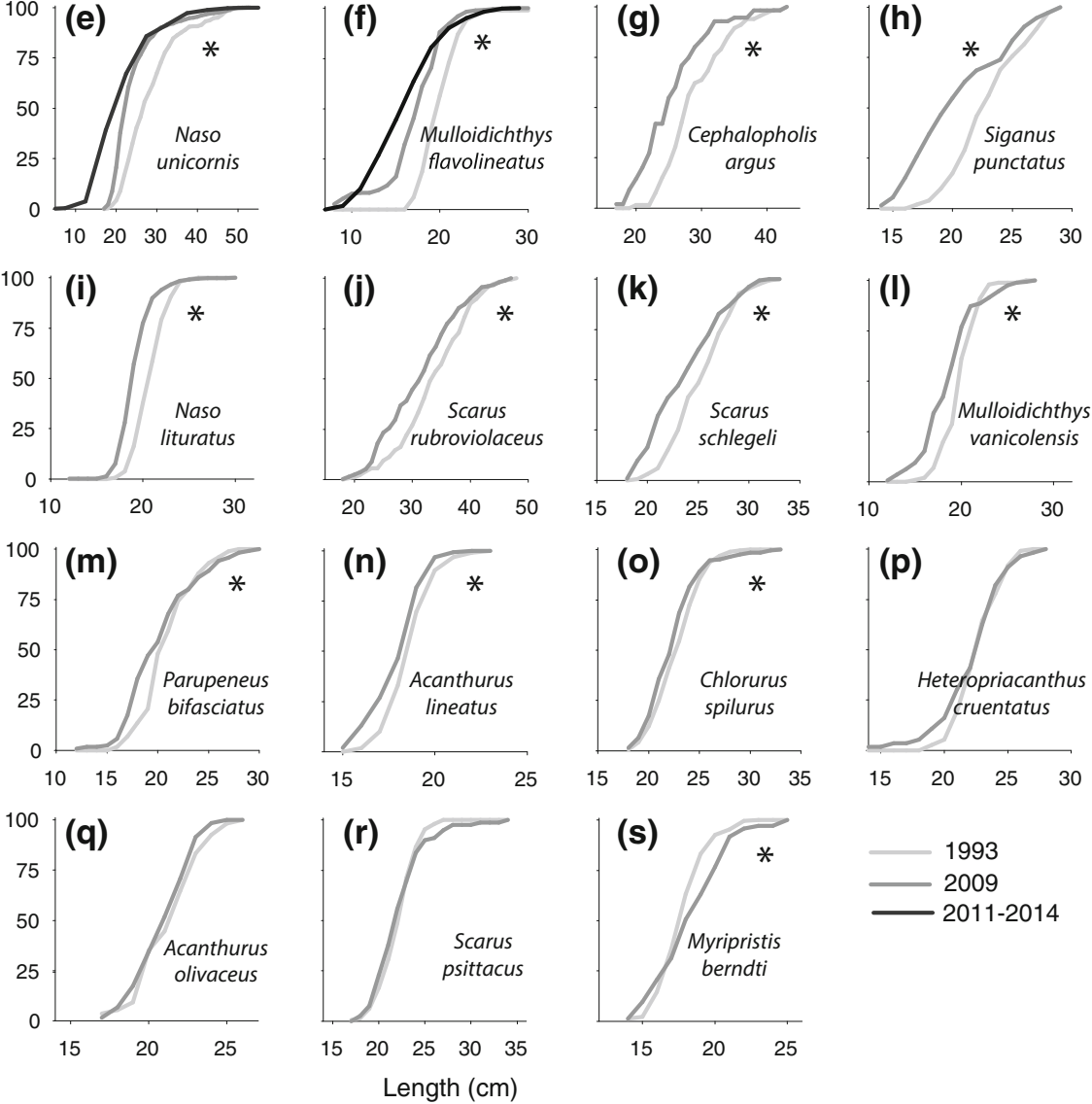

were an artifact of demand-driven commercial fish sales, but stable landings were associated with increased catch variability attributed to intermittent access to further, remote fishing grounds. Importantly, stable commercial catches may have provided a false sense of sustainability for consumers and managers.

Fishing variability has previously been identified as a useful indicator of fisheries status. Yet, studies to date have focused mostly on how truncated age structures can drive increased variability because of the growing reliance placed upon annual recruitment that becomes more dependent on variation in annual environmental cycles (Hsieh et al. 2006; Anderson et al. 2008). The present results offered that variability can also arise from environmental cycles that dictate access to more remote locations. As a result, fisheries expansions can mask localized depletions that are not recorded in most historical landings datasets (Crona et al. 2016; Cuetos-Bueno et al. 2018). We conclude that examining even coarse monthly landing records through time with respect to environmental regimes can provide one indication of localized depletions that corresponded with size-and-age structure shifts and are desirable for further research.

Size reductions were observed for $80 \%$ of target species, with greatest impacts to large-bodied species. While size reductions can reflect compensatory density-dependent responses that increase fisheries 


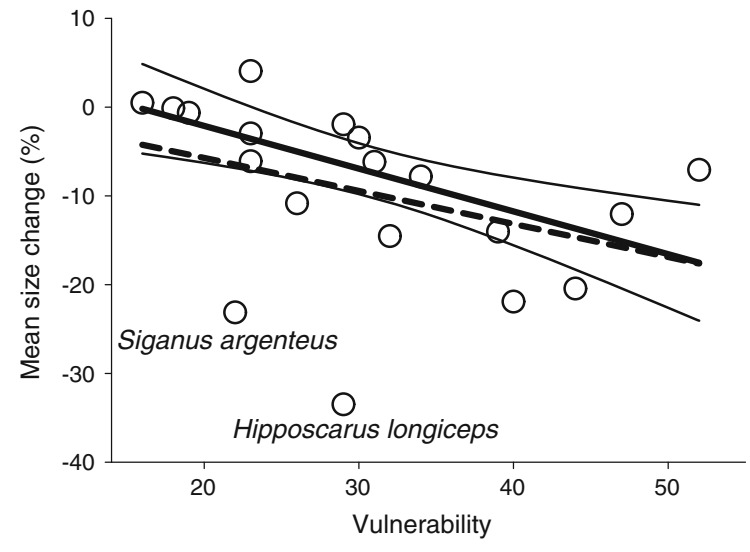

Fig. 5 Negative relationships between species vulnerability indices (see Methods) and size change between 1993 and 2009. Regressions models were examined with (dashed line) and without (full line) Siganus argenteus and Hipposcarus longiceps

productivity, stocks can eventually become compromised as (1) fish are increasingly caught before reaching maximum cohort biomass gains, and (2) reproductive output is reduced to the point where recruitment success tracks annual environmental cycles and yields greater variability (Anderson et al. 2008; Houk et al. 2018a). Here, over $90 \%$ of fish landed from three-key species examined in 2009 with recently published life-history data were caught before reaching their optimal sizes (N. unicornis, H. longiceps, and $S$. argenteus). Harvesting below $\mathrm{L}_{\mathrm{opt}}$ reduces cohort biomass production and requires that larger numbers of smaller fish are needed to maintain stable landings, eventually reducing the population size. In support, three similar scenarios serve to describe the trends in landings of $S$. argenteus. Juvenile landings < 1-year old may have: (1) increased from 5\% in 1993 (Graham 1994a) to $81 \%$ in 2009 (Houk et al. 2012), (2) increased from 5 to $29 \%$ if considering the subset of $S$. argenteus landings selected for a recent life-history investigation (Taylor et al. 2016), or (3) increased from 5 to $37 \%$ considering the complete 2010-2015 dataset depicted in a recent technical report (Sundberg et al. 2015).

Interestingly, landings of both rabbitfishes and the iconic unicornfish (N. unicornis) showed significant size declines but the ratio of landings between calm and windy months did not change. These species may have a comparatively strong density-dependent responses making them more resilient to fishing pressure. Previous studies have shown their consistent contributions to overall landings despite size-structure shifts (Taylor et al. 2014b; Cuetos-Bueno et al. 2018; Houk et al. 2018b). Similarly, larger sizes of rudderfish, K. cinerascens, and goatfish, M. flavolineatus, found on the more populated island of Saipan compared to Rota and Tinian are consistent with a temporal study on Guam showing these species became more prolific with increasing fishing pressure over a 20 years period (Houk et al. 2018b). Identifying the relative resilience of target species to fishing pressure is clearly a desirable direction for future research.

\section{Management}

\section{Reconsidering spatial management units}

Findings from this study can help to refine common approaches to coral-reef fisheries management in CNMI and beyond. Spatial management units that provide one foundation for fisheries policies usually represent geo-political boundaries (i.e., entire or many islands including wave-exposure gradients; Sabater and Kleiber 2014). This delineation is the result of assumed genetic connectivity within geopolitical boundaries, without further consideration for population ecology or fisheries dynamics (Blackhart et al. 2006). While genetic connectivity among islands or differing wave exposure regimes may exist, this does not equate to ecological connectivity, as panmixia of metapopulations can be maintained even when exchange between populations is infrequent (Horne et al. 2013; Nadon et al. 2015; Hawkins et al. 2016; Williamson et al. 2016). In support, a growing number of studies have reported highly divergent populations of target fishes across the Mariana archipelago, suggesting limited ecological connectivity (CuetosBueno and Houk 2014; Houk et al. 2014; Williams et al. 2015). We suggest that spatial management units might instead be defined by demographic connectivity, aggregating populations from different locations into single management units only if demographic exchange exists at time scales relevant to processes that control population growth (Nadon et al. 2015; Hawkins et al. 2016). While commercial fisheries may be able to maintain landings alongside growing localized depletions, subsistence and recreational fishers may not be able to cope with increasing costs needed to access remote fishing grounds and may 
suffer more. This is concerning given the high reliance upon subsistence fishing for food security evidenced by the large ratio of subsistence-to-commercial fishing for island nations (3:1 subsistence-to-commercial ratio on average across the Pacific, and 5:1 to 10:1 for CNMI; Cuetos-Bueno and Houk 2014; Gillett 2016).

\section{Size-based management}

Size-based policies may best address species with strong density-dependence responses to fishing pressure (Houk et al. 2017). However, there are discrepancies regarding optimal catch sizes (Froese 2004). Mean size at maturity $\left(\mathrm{L}_{\mathrm{m}}\right)$ has been proposed as a non-conservative benchmark to reduce recruitment overfishing, and reliable estimates of $\mathrm{L}_{\mathrm{m}}$ can be obtained from life-history studies. More conservative targets to address recruitment, cohort biomass, and fecundity have been proposed by optimal catch sizes $\left(\mathrm{L}_{\mathrm{opt}}\right.$; Froese et al. 2016). However, $\mathrm{L}_{\mathrm{opt}}$ estimates are very sensitive to natural mortality $(\mathrm{M})$ rates that are dependent on an inconsistent metric, the oldest fish recorded when sampling (Froese et al. 2008; Hoenig 2017). The reliance on a parameter that can change with sampling effort and fishing pressure hampers the utility of $\mathrm{L}_{\mathrm{opt}}$. This situation similarly hampers other common fisheries benchmarks based on mortality

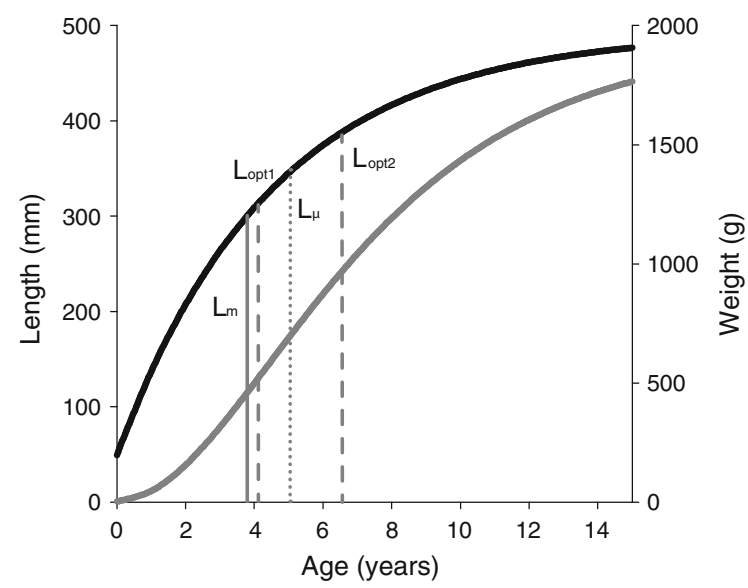

Fig. 6 Growth curve (weight: gray; length: black) of Naso unicornis with estimated: (i) mean age/length at maturity from Guam ( $\mathrm{L}_{\mathrm{m}}$; Taylor et al. 2014c), (ii) age/length at maximum growth rate $\left(\mathrm{L}_{\mu}\right)$, and (iii) different estimates of optimum age/ length at capture $\left(\mathrm{L}_{\mathrm{opt}}\right)$. $\mathrm{L}_{\mathrm{opt}}$ estimated using maximum length $\left(\mathrm{L}_{\text {opt } 1}\right.$; Froese and Binohlan 2000), and estimated based on maximum age recorded in Guam (23 years, $\mathrm{L}_{\mathrm{opt} 2}$; Beverton 1992; Taylor et al. 2014c) estimates, such as fishing-versus-natural mortality ratios and spawning potential ratios (Hordyk et al. 2014; Prince et al. 2015; Taylor et al. 2016, 2017). Alternatively, robust growth estimates $(\mathrm{K})$ are relatively easy to obtain, allowing for accurate estimation of length at maximum growth rate $\left(\mathrm{L}_{\mu}\right)$. We suggest that given potential issues with the $\mathrm{L}_{\text {opt }}$ benchmark, fisheries managers might conservatively consider the largest of these three benchmarks $\left(\mathrm{L}_{\mathrm{opt}}, \mathrm{L}_{\mathrm{m}}\right.$ or $\left.\mathrm{L}_{\mu}\right)$ as starting points for adaptive policies to address the current situation in CNMI and beyond.

\section{Lessons from customary management practices}

Traditional management in the Marianas and across the wider Pacific was based on small-scale, spatiallydisconnected fisheries units that were managed under reef tenure systems (Johannes 1978; Ruddle et al. 1992). Within each system, similar fisheries practices were derived from an intimate knowledge of speciesspecific responses to fishing pressure (Johannes 1981). This led to rights-based fishing for individuals to target certain species at specific seasonal cycles and specific growth stages (Kerr 2011). These approaches provided for sustainable harvesting regimes and food security with potentially higher harvesting rates than at present (Mcclenachan and Kittinger 2013). While traditional fishing practices may be impossible to bring back, policies that address spatial footprints such as comanagement or rights-based access could provide a means to improve small scale reef fisheries across the tropical Pacific that resonates with traditional fishing practices (Johannes 1981).

\section{Conclusions}

We conclude that a consistent supply of reef-fish to commercial markets masked fisheries expansions in the CNMI that were linked with diminishing size structures for most target species. While fisheries expansion may take longer to impact commercial markets, subsistence fishers may not be able to cope with increasing costs needed to access remote fishing grounds, and their food security may decline. Reconsidering fundamental fisheries management principles regarding spatial management units and size policies can help to address the observed situation in CNMI, and likely for fisheries elsewhere. We conclude that 
reconsideration of these policies would not only be scientifically sound, but also resonate with traditional knowledge and have a greater social acceptance.

Acknowledgements This study was funded through a National Oceanic and Atmospheric Administration Coral Conservation Grant administered to $\mathrm{PH}$ and JCB (NA16NOS4820055). We are grateful for the dedication of CNMI Nutritional Assistance Program and fish vendors who provided the historical data used in this study. We are also grateful to the local resource managers and fishers in CNMI who have shared their opinions and information over the years, provided constructive criticism, and continue to share their knowledge through conversation.

Open Access This article is distributed under the terms of the Creative Commons Attribution 4.0 International License (http:// creativecommons.org/licenses/by/4.0/), which permits unrestricted use, distribution, and reproduction in any medium, provided you give appropriate credit to the original author(s) and the source, provide a link to the Creative Commons license, and indicate if changes were made.

\section{References}

Abesamis RA, Green AL, Russ GR, Jadloc CRL (2014) The intrinsic vulnerability to fishing of coral reef fishes and their differential recovery in fishery closures. Rev Fish Biol Fish 24:1033-1063. https://doi.org/10.1007/s11160-0149362-x

Albert S, Aswani S, Fisher PL, Albert J (2015) Keeping food on the table: human responses and changing coastal fisheries in Solomon islands. PLoS ONE 10:e0130800. https://doi. org/10.1371/journal.pone.0130800

Amesbury JR, Hunter-Anderson RL (2003) Review of archaeological and historical data concerning reef fishing in the U.S. Flag Islands of Micronesia: Guam and the Northern Mariana Islands. Western Pacific Regional Fishery Management Council report

Anderson CNK, Hsieh C, Sandin SA et al (2008) Why fishing magnifies fluctuations in fish abundance. Nature 452: 835-839

Beverton RJH (1992) Patterns of reproductive strategy parameters in some marine teleost fishes. J Fish Biol 41:137-160. https://doi.org/10.1111/j.1095-8649.1992.tb03875.x

Birkeland C (2004) Ratcheting down the coral reefs. Bioscience 54:1021-1027. https://doi.org/10.1641/0006-3568(2004) 054\%5b1021:RDTCR\%5d2.0.CO;2

Birkeland C (2017) Working with, not against, coral-reef fisheries. Coral Reefs 36:1-11. https://doi.org/10.1007/ s00338-016-1535-8

Birkenbach AM, Kaczan DJ, Smith MD (2017) Catch shares slow the race to fish. Nature 544:223-226. https://doi.org/ 10.1038 /nature21728

Blackhart K, Stanton DGD, Shimada AM (2006) NOAA fisheries glossary. United States Department of Commerce,
National Oceanic and Atmospheric Administration, Silver Spring

Cheung W, Pitcher TJ, Cheung WWL et al (2005) A fuzzy logic expert system to estimate intrinsic extinction vulnerabilities of marine fishes to fishing extinction vulnerabilities of marine fishes to fishing. Biol Convers 124:97-111. https:// doi.org/10.1016/j.biocon.2005.01.017

Cinner JE, Huchery C, MacNeil MA et al (2016) Bright spots among the world's coral reefs. Nature 535:416-419. https://doi.org/10.1038/nature18607

Claro R, de Mitcheson YS, Lindeman KC, García-Cagide AR (2009) Historical analysis of Cuban commercial fishing effort and the effects of management interventions on important reef fishes from 1960-2005. Fish Res 99:7-16. https://doi.org/10.1016/j.fishres.2009.04.004

Crona BI, Daw TM, Swartz W et al (2016) Masked, diluted and drowned out: how global seafood trade weakens signals from marine ecosystems. Fish Fish 17:1175-1182. https:// doi.org/10.1111/faf.12109

Cuetos-Bueno J, Houk P (2014) Re-estimation and synthesis of coral-reef fishery landings in the Commonwealth of the Northern Mariana Islands since the $1950 \mathrm{~s}$ suggests the decline of a common resource. Rev Fish Biol Fish 25:179-194. https://doi.org/10.1007/s11160-014-9358-6

Cuetos-Bueno J, Houk P (2017) Disentangling economic, social, and environmental drivers of coral-reef fish trade in Micronesia. Fish Res 199:263-270. https://doi.org/10. 1016/j.fishres.2017.10.010

Cuetos-Bueno J, Hernandez-Ortiz D, Graham C, Houk P (2018) Human and environmental gradients predict catch, effort, and species composition in a large Micronesian coral-reef fishery. PLoS ONE 13:e0198068. https://doi.org/10.1371/ journal.pone.0198068

Duenas \& Associates I (1997) Saipan lagoon use management plan. Survey of sea cucumbers and fish in the Saipan lagoon, Northern Mariana Islands (NMI)

Eggleston DB, Johnson EG, Kellison GT, Nadeau DA (2003) Intense removal and non-saturating functional responses by recreational divers on spiny lobster Panulirus argus. Mar Ecol Prog Ser 257:197-207

Froese R (2004) Keep it simple: three indicators to deal with overfishing. Fish Fish 5:86-91. https://doi.org/10.1111/j. 1467-2979.2004.00144.x

Froese R, Binohlan C (2000) Empirical relationships to estimate asymptotic length, length at first maturity and length at maximum yield per recruit in fishes, with a simple method to evaluate length. J Fish Biol 56:758-773. https://doi.org/ 10.1006/jfbi.1999.1194

Froese R, Pauly D (2016) FishBase. www.fishbase.org. Accessed April 2018

Froese R, Stern-Pirlot A, Winker H, Gascuel D (2008) Size matters: how single-species management can contribute to ecosystem-based fisheries management. Fish Res 92:231-241. https://doi.org/10.1016/j.fishres.2008.01.005

Froese R, Winker H, Gascuel D et al (2016) Minimizing the impact of fishing. Fish Fish 17:785-802. https://doi.org/10. 1111/faf.12146

Gillett RE (2016) Fisheries in the economies of Pacific Island Countries and Territories, Second. Pacific Community (SPC), Nouméa 
Graham T (1994a) Biological analysis of the nearshore reef fishery of Saipan and Tinian. Commonwealth of the Northern Mariana Islands Division of Fish and Wildlife Technical Report 94-02. http://www.cnmi-dfw.com/docs/ 1994-02\%20Biological\%20Analysis\%20of\%20the\% 20Nearshore $\% 20$ Reef $\% 20$ Fish $\% 20$ Fishery $\% 20$ of $\%$ 20Saipan\%20and\%20Tinian.pdf

Graham T (1994b) Reef fish resources of the CNMI: a review of the fisheries, research and management. Commonwealth of the Northern Mariana Islands Division of Fish and Wildlife Technical Report 94-03. http://www.cnmi-dfw.com/docs/ 1994-03\%20Reef\%20Fish\%20Resources\%20of\%20the\% 20CNMI.pdf

Graham NAJ, Wilson SK, Jennings S et al (2007) Lag effects in the impacts of mass coral bleaching on coral reef fish, fisheries, and ecosystems. Conserv Biol 21:1291-1300

Hawkins SJ, Bohn K, Sims DW et al (2016) Fisheries stocks from an ecological perspective: disentangling ecological connectivity from genetic interchange. Fish Res 179:333341. https://doi.org/10.1016/j.fishres.2016.01.015

Hernandez-Ortiz D, Houk P, Rhodes K, Cuetos-Bueno J (2016) Characteristics and drivers of coral-reef fishery landings in Pohnpei, Federated States of Micronesia. In: Proceedings of 13th international coral reef symposium

Hoenig JM (1983) Empirical use of longevity data to estimate mortality rates. Fish Bull 82:898-903

Hoenig JM (2017) Should natural mortality estimators based on maximum age also consider sample size? Trans Am Fish Soc 146:136-146. https://doi.org/10.1080/00028487.2016. 1249291

Hordyk A, Ono K, Valencia S et al (2014) A novel length-based empirical estimation method of spawning potential ratio (SPR), and tests of its performance, for small-scale, datapoor fisheries. ICES J Mar Sci 72:217-231. https://doi.org/ 10.1093/icesjms/fsu004

Horne JB, Van Herwerden L, Abellana S, Mcilwain JL (2013) Observations of migrant exchange and mixing in a coral reef fish metapopulation link scales of marine population connectivity. J Hered 104:532-546. https://doi.org/10. 1093/jhered/est021

Houk P, Rhodes K, Cuetos-Bueno J et al (2012) Commercial coral-reef fisheries across Micronesia: a need for improving management. Coral Reefs 31:13-26. https://doi.org/10. 1007/s00338-011-0826-3

Houk P, Benavente D, Iguel J et al (2014) Coral reef disturbance and recovery dynamics differ across gradients of localized stressors in the Mariana Islands. PLoS ONE 9:e110068. https://doi.org/10.1371/journal.pone.0110068

Houk P, Tilfas R, Luckymis M et al (2017) An applied framework to assess exploitation and guide management of coral-reef fisheries. Ecosphere 8:e01727. https://doi.org/ $10.1002 /$ ecs 2.1727

Houk P, Cuetos-Bueno J, Kerr AM, McCann K (2018a) Linking fishing pressure with ecosystem thresholds and food web stability on coral reefs. Ecol Monogr 88:109-119. https:// doi.org/10.1002/ecm.1278

Houk P, Cuetos-Bueno J, Tibbatts B, Gutierrez J (2018b) Variable density dependence and the restructuring of coralreef fisheries across 25 years of exploitation. Sci Rep 8:5725. https://doi.org/10.1038/s41598-018-23971-6
Hsieh C, Reiss CS, Hunter JR et al (2006) Fishing elevates variability in the abundance of exploited species. Nature 443:859-862. https://doi.org/10.1038/nature05232

Huang BL, Smith MD, Timmins C et al (2014) The dynamic efficiency cost of common-pool resource exploitation. Am Econ Rev 104:4071-4103

Jenks GF, Coulson MRC (1963) Class intervals for statistical maps. In: International Yearbook of Cartography, pp 119-34

Jennings S, Greenstreet SPR, Reynolds JD (1999) Structural change in an exploited fish community: a consequence of differential fishing effects on species with contrasting life histories. J Anim Ecol 68:617-627. https://doi.org/10. 1046/j.1365-2656.1999.00312.x

Johannes RE (1978) Traditional marine conservation methods in Oceania and their demise. Annu Rev Ecol Syst 9:349-364

Johannes RE (1981) Words of the lagoon: fishing and marine lore in the Palau district of Micronesia. University of California Press, Berkeley

Jupiter SD, Weeks R, Jenkins AP et al (2012) Effects of a single intensive harvest event on fish populations inside a customary marine closure. Coral Reefs 31:321-334. https:// doi.org/10.1007/s00338-012-0888-x

Kaunda-Arara B, Rose GA, Muchiri MS, Kaka R (2003) Longterm trends in coral reef fish yields and exploitation rates of commercial species from Coastal Kenya. West Indian Ocean J Mar Sci 2:105-116

Kerr MA (2011) Fishing methods of the Mariana islands. Univ Guam Mar Lab Techincal Rep, Micronesia, p 132

Lindfield SJ, Harvey ES, Halford AR, McIlwain JL (2015) Mesophotic depths as refuge areas for fishery-targeted species on coral reefs. Coral Reefs 35:125-137. https://doi. org/10.1007/s00338-015-1386-8

Lowe MK, Quach MMC, Brousseau KR, Tomita AS (2016) Fishery Statistics of the Western Pacific. Pac Islands Fish Sci Cent Admin Rep. https://doi.org/10.7289/V5/AR-H16-03

McClanahan TR, Mangi S (2000) Spillover of exploitable fishes from a marine park and its effect on the adjacent fishery. Ecol Appl 10:1792-1805

Mcclenachan L, Kittinger JN (2013) Multicentury trends and the sustainability of coral reef fisheries in Hawai'i and Florida. Fish Fish 14:239-255. https://doi.org/10.1111/j.14672979.2012.00465.x

McLean M, Cuetos-Bueno J, Nedlic O et al (2016) Local stressors, resilience, and shifting baselines on coral reefs. PLoS ONE 11:e0166319

Nadon MO, Ault JS, Williams ID et al (2015) Length-based assessment of coral reef fish populations in the Main and Northwestern Hawaiian Islands. PLoS ONE 10:e0133960

Pauly D, Zeller D (2014) Accurate catches and the sustainability of coral reef fisheries. Curr Opin Environ Sustain 7:44-51. https://doi.org/10.1016/j.cosust.2013.11.027

Pauly D, Christensen V, Dalsgaard J et al (1998) Fishing down marine food webs. Science 279:860-863

Prince J, Victor S, Kloulchad V, Hordyk A (2015) Length based SPR assessment of eleven Indo-Pacific coral reef fish populations in Palau. Fish Res 171:42-58. https://doi.org/ 10.1016/j.fishres.2015.06.008 
Radtke H, Davis S (1995) Analysis of Saipan's seafood markets. A report for Commonwealth of the Northern Mariana Islands Division of Fish and Wildlife. September 1995

Reynolds T, Burdick D, Houk P et al (2014) Unprecedented coral bleaching across the Marianas Archipelago. Coral Reefs 33:499. https://doi.org/10.1007/s00338-014-1139-0

Rhodes KL, Hernandez-Ortiz DX, Cuetos-Bueno J et al (2018) A 10-year comparison of the Pohnpei, Micronesia, commercial inshore fishery reveals an increasingly unsustainable fishery. Fish Res 204:156-164

Rosenberg AA (2017) Marine conservation: the race to fish slows down. Nature 544:165-166. https://doi.org/10.1038/ nature 21906

Ruddle K, Hviding E, Johannes RE (1992) Marine resources management in the context of customary tenure. Mar Resour Econ 7:249-273

Sabater M, Kleiber P (2014) Augmented catch-MSY approach to fishery management in coral-associated fisheries. In: Bortone SA (ed) Interrelations between corals and fisheries. CRC Press, Boca Raton, FL, pp 199-218

Shin YJ, Rochet MJ, Jennings S et al (2005) Using size-based indicators to evaluate the ecosystem effects of fishing. ICES J Mar Sci 62:384-396. https://doi.org/10.1016/j. icesjms.2005.01.004

Smith RO (1947) Survey of the fisheries of the former Japanese Mandated Islands. United States Department of the Interior, Fish and Wildlife Service, Washington

Smith SH, Marx DE (2016) De-facto marine protection from a Navy bombing range: farallon De Medinilla, Mariana Archipelago, 1997 to 2012. Mar Pollut Bull 102:187-198. https://doi.org/10.1016/j.marpolbul.2015.07.023

Sundberg M, Humphreys R, Lowe MK, Gourley J (2015) Status of life history sampling conducted through the commercial fisheries bio-sampling programs in the Western Pacific Territories of American Samoa, Guam, and in the Commonwealth of the Northern Mariana Islands

Swartz W, Sala E, Tracey S et al (2010) The spatial expansion and ecological footprint of fisheries (1950 to present). PLoS ONE 5:3-8. https://doi.org/10.1371/journal.pone. 0015143

Sys K, Van Meensel J, Polet H, Buysse J (2017) A temporal race-for-fish: the interplay between local hotspots of flatfish and exploitation competition between beam trawlers after a seasonal spawning closure. Fish Res 193:21-32. https://doi.org/10.1016/j.fishres.2017.03.018

Taylor BM, Cruz E (2017) Age-based and reproductive biology of the Pacific Longnose Parrotfish (Hipposcarus longiceps) from Guam. PeerJ 5:e4079. https://doi.org/10.7717/peerj. 4079

Taylor BM, Houk P, Russ GR, Choat JH (2014a) Life histories predict vulnerability to overexploitation in parrotfishes.
Coral Reefs 33:869-878. https://doi.org/10.1007/s00338014-1187-5

Taylor BM, Lindfield SJ, Choat JH (2014b) Hierarchical and scale-dependent effects of fishing pressure and environment on the structure and size distribution of parrotfish communities. Ecography (Cop) 38:520-530. https://doi. org/10.1111/ecog.01093

Taylor BM, Rhodes KL, Marshell A, Mcilwain JL (2014c) Agebased demographic and reproductive assessment of orangespine Naso lituratus and bluespine Naso unicornis unicornfishes. J Fish Biol 85:1-16. https://doi.org/10.1111/ jfb. 12479

Taylor BM, Gourley J, Trianni MS (2016) Age, growth, reproductive biology and spawning periodicity of the forktail rabbitfish (Siganus argenteus) from the Mariana Islands. Mar Freshw Res 68:1088-1097

Taylor BM, Oyafuso ZS, Trianni MS (2017) Life history of the orange-striped emperor Lethrinus obsoletus from the Mariana Islands. Ichthyol Res 64:423-432. https://doi.org/ 10.1007/s10228-017-0573-8

Teh L, Zeller D, Cabanban A et al (2007) Seasonality and historic trends in the reef fisheries of Pulau Banggi, Sabah, Malaysia. Coral Reefs 26:251-263. https://doi.org/10. 1139/xxxx

Trianni MS (1998) Summary and further analysis of the nearshore reef fishery of the Northern Mariana Islands. CNMI Division of Fish and Wildlife technical report

Trianni MS, Gourley JE, Ramon MS (2018) Spatial, temporal, and biological characteristics of a nearshore coral reef fishery in the northern Mariana islands. Mar Coast Fish 10:283-297. https://doi.org/10.1002/MCF2.10024

U.S. Census Bureau (2014) 2010 Census of Population and Housing, Commonwealth of the Northern Mariana Islands Summary File: Technical Documentation

Van Beukering P, Haider W, Wolfs E et al (2006) The economic value of the coral reefs of Saipan, commonwealth of the northern Mariana islands. Cesar Environmental Economics Consulting, Arnhem

Williams ID, Walsh WJ, Miyasaka A, Friedlander AM (2006) Effects of rotational closure on coral reef fishes in WaikikiDiamond Head Fishery Management Area, Oahu, Hawaii. Mar Ecol Prog Ser 310:139-149. https://doi.org/10.3354/ meps310139

Williams ID, Baum JK, Heenan A et al (2015) Human, oceanographic and habitat drivers of central and western pacific coral reef fish assemblages. PLoS ONE 10:1-19. https://doi.org/10.1371/journal.pone.0120516

Williamson DH, Harrison HB, Almany GR et al (2016) Largescale, multidirectional larval connectivity among coral reef fish populations in the Great Barrier Reef Marine Park. Mol Ecol 25:6039-6054. https://doi.org/10.1111/mec.13908 